\section{G627 \\ STUDY TO INVESTIGATE THE EFFECTIVENESS OF USING A HUMANOID ROBOT (KASPAR) TO IMPROVE THE SOCIAL SKILLS OF CHILDREN WITH AN AUTISM SPECTRUM DISORDER (ASD): A RANDOMISED CONTROLLED FEASIBILITY TRIAL}

${ }^{1} \mathrm{~K}$ Irvine, 'S Mengoni, ${ }^{2} \mathrm{D}$ Thakur, 'S Sharma. 'Department of Psychology and Sport Sciences, University of Hertfordshire, Hatfield, UK; ${ }^{2}$ Department of Community Paediatrics, Hertfordshire Community NHS Trust, Welwyn Garden City, UK

\subsection{6/archdischild-2020-rcpch.541}

Aims A growing body of research has shown that robots can be effective in improving the social communication skills of children with ASD, however randomised controlled trials (RCTs) are lacking. This feasibility RCT examined whether it is possible to deliver a social skills intervention using the Kaspar robot with children with ASD within the NHS.

Method Children with ASD aged between 5-10 took part in six therapy sessions targeting key social communication skills with a therapist. Children were randomised to therapy using the robot or with the therapist only. Parental stress and the child's social skills were assessed at three time points, using parent-reported questionnaires and video analysis.

Results The criteria for recruitment and data collection were met. Forty-five percent of those sent details of the study (42/ 94) agreed to take part. Of these, 38 were randomised and a further seven withdrew post-randomisation: an attrition rate of $26 \%$. More than $80 \%$ of the questionnaires were completed. Some technical issues arose, which could be addressed in a full-scale study. Feedback from parents and clinicians was positive.

Conclusion The findings confirm the feasibility of a full-scale trial to determine whether Kaspar is an effective social skills intervention for children with ASD in an NHS setting.

\section{G628 A RETROSPECTIVE STUDY TO UNDERSTAND EMERGING THEMES FROM USING LONG ACTING GUANFACINE - NON STIMULANT MEDICATION IN 70 CHILDREN AND YOUNG PEOPLE WITH ADHD (ATTENTION DEFICIT HYPERACTIVITY DISORDER) IN A SECONDARY CARE SETTING}

${ }^{1} \mathrm{R}$ Jainer, ${ }^{1} \mathrm{~B}$ Wilkins, ${ }^{1,2} \mathrm{C}$ Yemula. ${ }^{1}$ Department of Paediatrics, University Hospitals of Birmingham NHS Trust,Solihull, UK; ' Department of Paediatrics, Union Street Clinic,Bedford, UK

\subsection{6/archdischild-2020-rcpch.542}

Aims As most clinicians have limited experience and are still not confident about using Guanfacine since its license in 2016 in Uk, this study was undertaken to identify any emerging themes-any gender differences, comorbid factros and side effects whihc could impact on its usage.

Method Data was collected from clinical notes on all our patients on Guanfacine over the past one year.

This study looked at demographics, co morbidity, tolerance and dosage needed.

Emerging themes were identified in addition which could inform future studies on use of Guanfacine.

Results Age range $4-15$ years (12 girls and 58 boys) received treatment with Guanfacine.
Comorbidity was seen in 48 patients (69\%): Autism spectrum disorder was commonest (16), Developmental coordination disorder (13), Leaning disability (10) some had other conditions e.g. Conduct disorder, tic disorder, dyslexia.

Guanfacine was discontinued in 36 patients (51\%), the commonset side effect was sedation in 20 patients $(29 \%)$ and other reasons for discontinuation included headaches, aggressive behaviour and ineffective control of ADHD symptoms.

The success rate was $98.8 \%$ in teenage girls.

The dose range was $1 \mathrm{mg}$ (19) to $6 \mathrm{mg}$ (1), and most patients (36) needed 2 to $3 \mathrm{mg}$ for effective control of symptoms.

Conclusion It is small observational study and would be useful to have larger studies comparing the side effects and efficacy of low dose Guanfaicne in teenage girls specifically across different regions.

Recommendations Low dose polytherapy regimes along with stimulant medication which would minimise side effects and improve overall efficacy should be explored in UK as is proven to be effective in other countries.

\section{G629(P) PILOT STUDY OF NEURODEVELOPMENTAL DIAGNOSTIC CLINIC MODEL IN SCHOOL-AGED CHILDREN, FOR WHOM THERE IS DIAGNOSTIC UNCERTAINTY REGARDING THE PRESENCE OF AUTISTIC SPECTRUM DISORDER}

${ }^{1} \mathrm{~L}$ Austreng, ${ }^{1} \mathrm{C}$ McAuley, ${ }^{2} \mathrm{~V}$ Thurston, ${ }^{1} \mathrm{~S}$ de Gressi. ${ }^{1} \mathrm{Community}$ Paediatrics, Gloucestershire Hospitals NHS FT, Gloucester, UK; ${ }^{2}$ Child and Young Person Service, 2Gether NHS FT, Gloucester, UK

\subsection{6/archdischild-2020-rcpch.543}

Background Locally, neurodevelopmental assessment of primary school aged children with social and communication difficulties involves collation of reports from the educational setting, then assessment by a paediatrician. Often, no formal diagnostic tool or face-to-face multi-professional assessment is carried out. For some children, this model of working can lead to a delay in conclusions due to complexities with that child. This pilot was a model for multi-professional working between a paediatrician and clinical psychologist using structured assessments for a group of children that presented diagnostic challenge.

Aims To pilot a neurodevelopmental clinical model of joint working between a paediatrician and psychologist. To collect data regarding clinician and patient experience, time from initial referral to diagnosis and identify the advantages and pitfalls of this method of working. To provide information for the MDT reviewing the pathway for Autistic Spectrum Disorder (ASD) diagnosis.

Method Cases were selected by the paediatrician. Data collected included demographics, presenting problems, time from referral to receiving a final diagnosis, diagnostic outcome and experience feedback questionnaires. Diagnostic Interview for Social and Communication Disorders (DISCO) and Autism Diagnostic Observation Schedule (ADOS) assessments were carried out.

Results Thirteen children were enrolled in the pilot from 2017 to 2019 with a median age of nine years, four months. Eleven participants were male. Five of the children were given a final diagnosis of ASD. Other children received a 